\title{
Primary hyperoxaluria: Orthodontic management in a pediatric patient: A case report
}

\author{
A. P. Cazzolla DDS, $\mathrm{PhD}^{1}$ (D) | K. Zhurakivska DDS ${ }^{2}$ iD | D. Ciavarella DDS, $\mathrm{PhD}^{1} \quad$ \\ M. G. Lacaita MD, MSc ${ }^{1} \quad$ G. Favia MD, MSc ${ }^{1} \quad$ N. F. Testa MD, MSc ${ }^{2}$ ｜ \\ G. Marzo MD, MSc ${ }^{3} \quad$ V. La Carbonara DDS ${ }^{1} \quad$ G. Troiano DDS, PhD ${ }^{2} \quad$ L. Lo Muzio MD, MSc ${ }^{2}$
}

${ }^{1}$ Department of Odontostomatology and Surgery, University of Bari, Bari, Italy

${ }^{2}$ Department of Clinical and Experimental

Medicine, University of Foggia, Foggia, Italy

${ }^{3}$ Department of Life, Health and Environmental Sciences, Dental Clinic, University of L'Aquila, L'Aquila, Italy

\section{Correspondence}

Angela Pia Cazzolla, Clinica Odontoiatrica, Piazza Giulio Cesare, 11, 70124, Bari, Italy.

Email: elicio@inwind.it

\begin{abstract}
Aims: The aim of this study is to report the case of the orthodontic treatment in a
patient affected by primary hyperoxaluria type 1 and subjected to a combinate liver-
Abstract
Aims: The aim of this study is to report the case of the orthodontic treatment in a
patient affected by primary hyperoxaluria type 1 and subjected to a combinate liver-

Abstract
Aims: The aim of this study is to report the case of the orthodontic treatment in a
patient affected by primary hyperoxaluria type 1 and subjected to a combinate liverkidney transplant.

Methods and results: The 9-year patient was admitted to our department for the presence of facial dysmorphism. The patient was affected by primary hyperoxaluria type 1 and has undergone a combined liver-kidney transplantation. At the time of the visit, he was in treatment with immunosuppressive drugs and received a corticosteroid and an antibiotic therapy monthly. An intraoral and extraoral examination, as well as radiographic and model analysis, was performed in order to define an accurate diagnosis and a proper rehabilitation planning. An orthopedic-orthodontic treatment was performed and satisfactory final results obtained. A laser gingivectomy was also realized for eliminate the gengival hyperplasia probably induced by cyclosporine assumption. Both skeletal and dental relationships were improved by the treatment, reaching a good dental arches alignment.
\end{abstract}

Conclusion: An early diagnosis, as well as a multidisciplinary approach, is very important in patients with rare diseases. An appropriate treatment allowed us to achieve acceptable results and improve the patient quality of life.

\section{K E Y W O R D S}

orthodontics, pediatric dentistry, rare disorders

\section{1 | INTRODUCTION}

Primary hyperoxalurias $(\mathrm{PH})$ are a group of rare metabolic diseases with an autosomal recessive transmission, which causes an alteration of the glioxalate and oxalate metabolism. ${ }^{1}$ These conditions are characterized by an increased endogenous production of oxalate, a terminal metabolic product, which leads to an excessive urinary excretion of oxalate with consequent hyperoxaluria $\left(>0.5 \mathrm{mmol} / 1.73 \mathrm{~m}^{2}\right.$ per $\left.24 \mathrm{~h}\right)$ in comparison to the normal oxalate excretion $(<0.45 \mathrm{mmol} /$ $1.73 \mathrm{~m}^{2}$ per day), and formation of insoluble calcium oxalate crystals. The kidneys undergo progressive deterioration due to calcium oxalate deposition: urolithiasis, nephrocalcinosis, and end-stage renal disease (ESRD). The parenchymal deposition of oxalate (nephrocalcinosis) induces interstitial inflammation and fibrosis that result in progressive loss of renal function. ${ }^{2}$ The renal damage is followed by an increase of oxalate concentration in blood over its sovrasaturation level $(30 \mathrm{mmol} / \mathrm{L})$. 
speculate that further causes are yet to be identified. ${ }^{2} \mathrm{PH} 1$ is the most severe and common one (incidence 1:100 000 born alive per year in Europe). It is caused by the deficit of the liver peroxisomal enzyme: alanine-glioxylate amino transferase. ${ }^{3}$ $\mathrm{PH} 2$, rarest than the previous one, is due to a deficit of the cytosolic enzyme glyoxylate reductase/hydroxypyruvate reductase. ${ }^{4}$ Instead, PH3, of recent identification, is caused by a deficit of the mitochondrial enzyme 4-hydroxy-2oxoglutarate aldolase. ${ }^{5}$ These forms should be distinguished from the secondary hyperoxalurias, caused instead by an excessive ingestion of oxalate, its precursors or ascorbic acid, vitamin B6 (or piridoxin), or by an increased intestinal absorption, a repeated use of oral antibiotics that lead to oxalate elimination, professional exposure, both to oxalic acid (workers exposed to detergents and blanchers), both to ethilenic glicole (general anesthetic), and during hemodialysis. ${ }^{6}$

Around $80 \%$ of $\mathrm{PH}$ patients suffer $\mathrm{PH} 1$, characterized by systemic deposits of calcium oxalate monohydrate (ossalosis) at level of bones, heart, ocular tissue, tiroid, lymph nodes, skin, artery and venus walls, brain, meninges, and salivary glands and unless liver-kidney transplantation is performed, this condition quickly results in death in most patients. $^{7}$

Only about 10 cases described in the literature report oral manifestations in patients with hyperoxaluria. The age of the treated patients ranged between 7 and 55 years and the most common manifestation was represented by periodontal disease. ${ }^{8-10}$ The other oral findings described in patients with oxalosis, were: bone resorption in the jaws, external root resorption, and rapidly progressive dental mobility, as well as dental pain associated with deposition of oxalate in the dentine and the pulp. ${ }^{11}$ All these findings make the therapeutic approach more difficult than that of healthy patients. Furthermore, like stated by American Academy of Pediatric Dentistry, the most frequently documented source of sepsis in the immunosuppressed patient is the mouth. ${ }^{12}$ For this reasons, every patient who will receive an immunosuppressive therapy should be evaluated by dental specialists to define an appropriate approach. In particular, regarding the orthodontic appliances, the guidelines define that poorly-fitting appliances can abrade oral mucosa and increase the risk of microbial invasion into deeper tissues. Appliances should be removed if the patient has poor oral hygiene, while in patients who present good hygiene simple appliances (eg, band and loops, fixed lower lingual arches) that are not irritating to the soft tissues may be left in place. If possible, removable appliances and retainers should be preferred to the fixed ones and may be worn as long as tolerated by the patients. ${ }^{13}$

The median age at initial symptoms of PH1 is 4 to 7 years in Europe. ${ }^{14}$ The pediatric form often presents as a lifethreatening condition because of rapid progression to ESRD; at the time of the diagnosis $50 \%$ of the patients experience ESRD and $80 \%$ develop it by the age of 3 years. ${ }^{15}$
The diagnosis is performed by following elements: sonographic examination that may show either cortical or medullary nephrocalcinosis, ${ }^{16}$ stone passage, nephrocalcinosis, and renal impairment. Crystalluria and infrared spectroscopy are of major interest for identification and quantitative analysis of crystals and stones. ${ }^{17}$ In patients with normal or significant residual glomerular filtration rate (GFR), concomitant hyperoxaluria (urine oxalate $>1 \mathrm{mmol} / 1.73 \mathrm{~m}^{2}$ per day, reference value $0.5 \mathrm{mmol} / 1.73 \mathrm{~m}^{2}$ ) and hyperglycoluria (urine glycolate $>0.5 \mathrm{mmol} / 1.73 \mathrm{~m}^{2}$, reference value $<0.05$ ) are indicative of PH1, but some patients do not present hyperglycoluria. ${ }^{18}$

The treatment consists in an initial conservative approach, dialysis and organ transplantation for replacing the oxalateproducing liver and the kidney with a donor organ. ${ }^{2}$ The strategy of liver-kidney transplantation is influenced by the stage of the disease. ${ }^{19}$

The transplantation of organs often represents the only chance to save the life of these patients, however, it leads several complications. Some of these may be localized in the oral cavity.

Calcium-phosphate disturbances may affect the structure and metabolism of mandibular bones, promote calcification of dental pulp, and in children may cause developmental defects of teeth. ${ }^{20}$

There is also a positive correlation between discoloration of the deciduous teeth and liver transplantation and between enamel hypoplasia and kidney transplantation. Pulp stones are more frequent in the kidney recipients than in liver-transplanted patients. ${ }^{20} \mathrm{~A}$ gingival overgrowth due to cyclosporine A (CsA) medication is widely reported in literature. CsA is ordinarily used as an effective immunosuppressive agent to prevent organ transplant rejection, as well as in the treatment of patients with adverse side effects including nephrotoxicity and hypertrichosis.

Recently, a new immunosuppressive agent, tacrolimus (TAC/FK 506), has been approved for use in solid organ transplants. The use of CsA or TAC shows no difference in enamel defects, discoloration, or caries experience. ${ }^{21}$

Another complication is posttransplantation bone disease which is present in most of patients, where low bone mineral density increases the risk of fractures. Frequently, bone loss occurs in the first year after the organ transplant, due to the adverse effects of immunosuppressive drugs and, in addition, due to the long period of immobilization. ${ }^{22}$

The aim of this study is to report the case of the orthodontic treatment in a small patient affected by PH1 and subjected to a combinate liver-kidney transplant.

\section{2 | CASE REPORT}

The young patient, F.R., was admitted to our department in 2005 when he was 9 years old for the presence of facial 

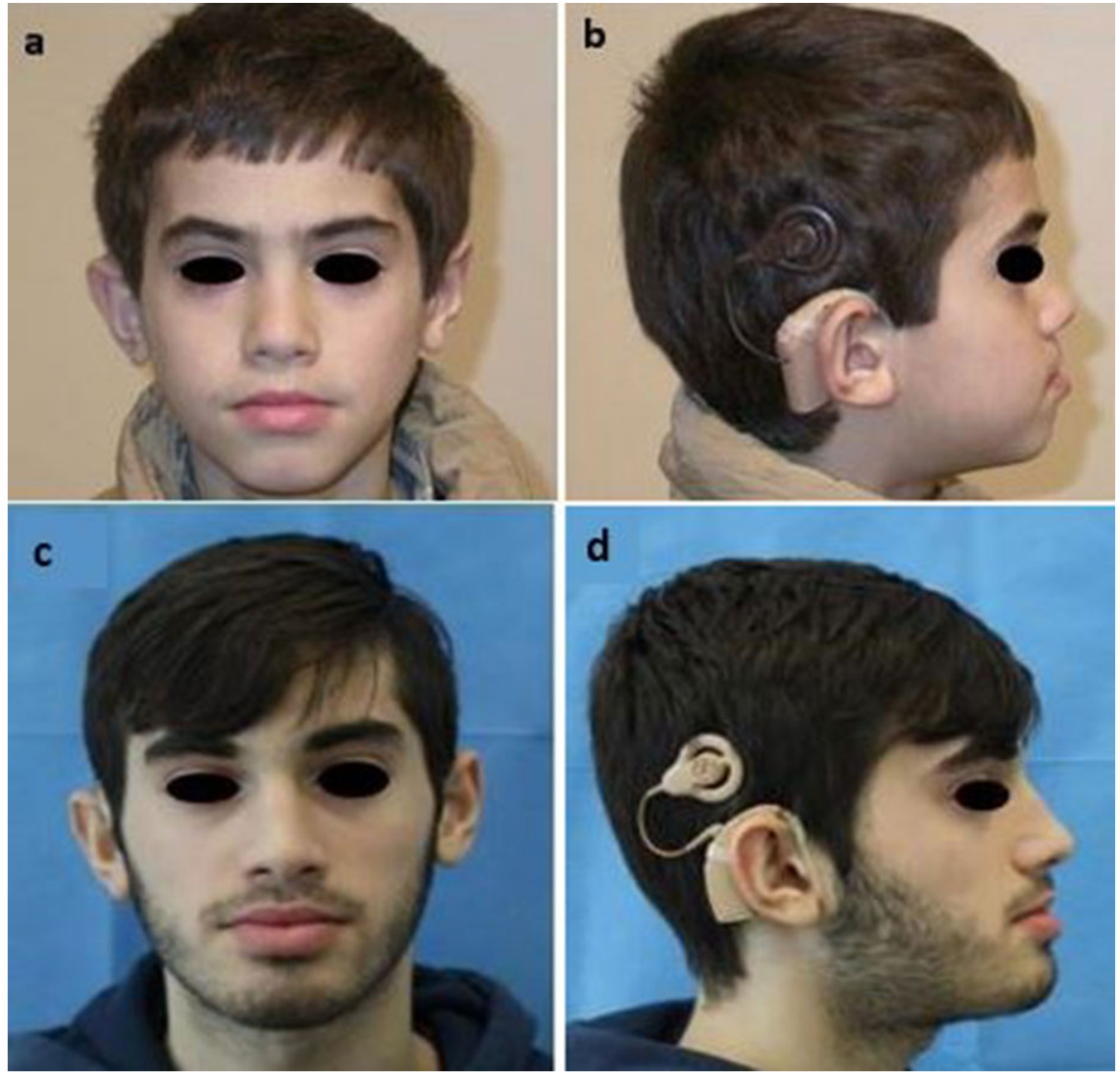

F I G U R E 1 Extraoral photo (a) frontal view before treatment; (b) lateral right view before treatment; (c) frontal view after treatment; (d) lateral right view after treatment
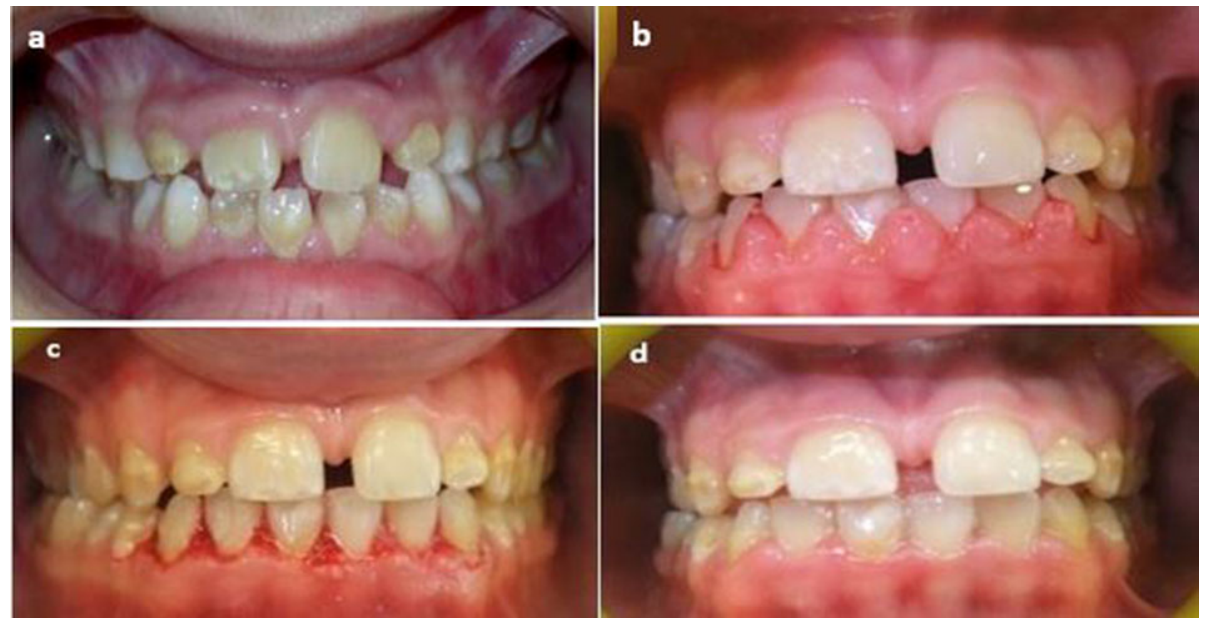

F I G U R E 2 Intraoral photo (a) before orthodontic treatment; (b) before the laser gingivectomy; (c) gingivectomy operation with laser application; (d) after healing

dysmorphism. In the anamnesis, the diagnosis of PH1 emerged. After the renal involvement linked to the disease, the patient has been subjected to dialysis from the age of 3 years and when he was 5 years old underwent a combinate liver-kidney transplantation.

At 7 years age a coclear implant insertion was performed, since a secondary drug-induced deafness had occurred.
At the moment of our examination, he was in therapy with immunosuppressive drugs (cyclosporine and mycophenolate mofetil), vitamin $\mathrm{D}$, sodium bicarbonate, and $\mathrm{K}$-based and Mg-based nutritional supplements. Moreover, he underwent a corticosteroid treatment and an antibiotic therapy monthly.

The extraoral objective structured clinical examination showed a symmetrical face with low-implant auricles and a 

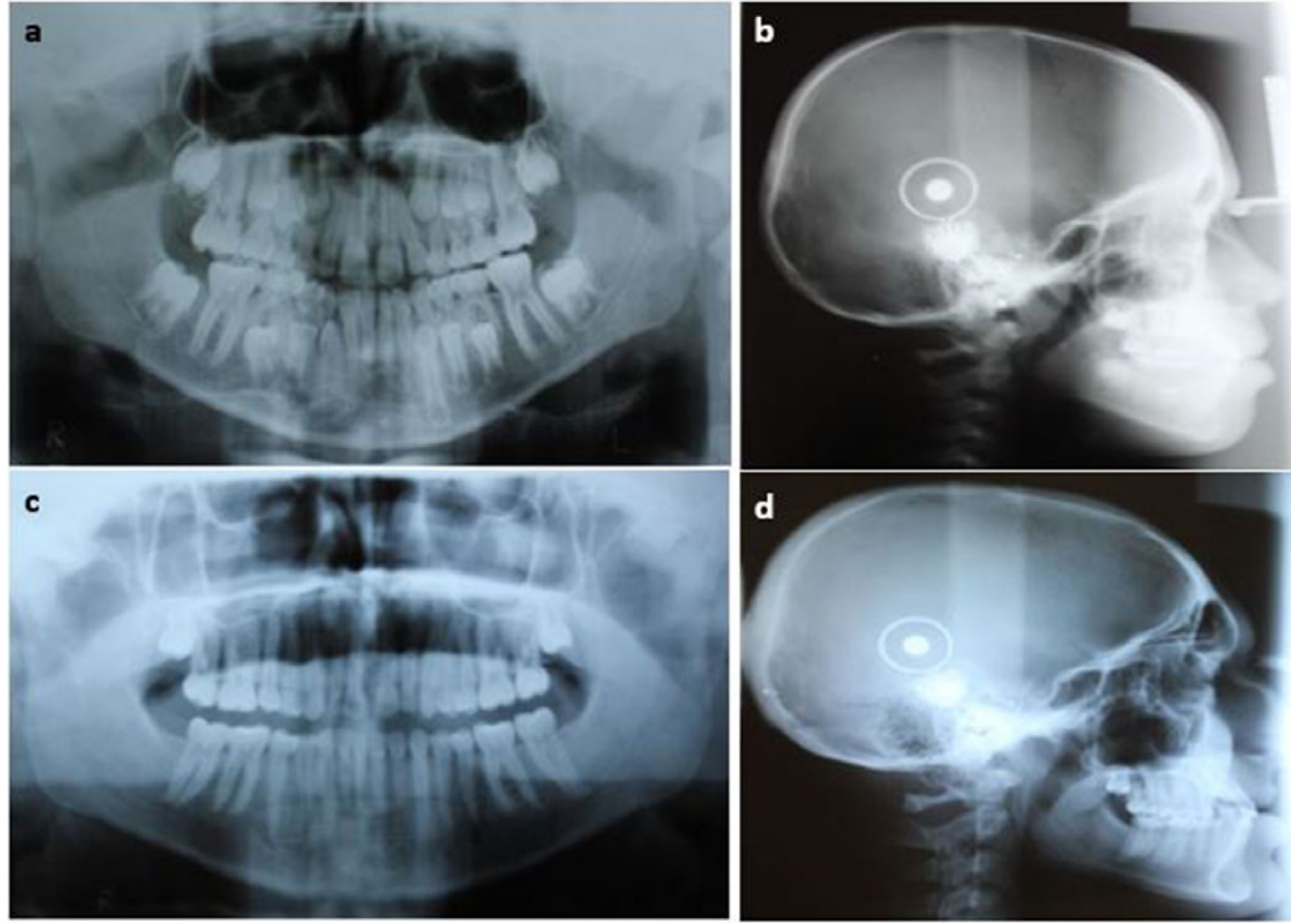

F I G URE 3 (a) Orthopantomography before treatment; (b) latero-lateral teleradiography of the head before treatment; (c) final orthopantomography; (d) final latero-lateral teleradiography of the head

concave profile with upper jaw hypoplasia (Figures 1a and 1b).

At intraoral examination (Figures $2 \mathrm{a}$ and $2 \mathrm{~b}$ ), the following findings were identified: a widespread enamel hypoplasias, Class III canine and molar dental relationship, upper diastema of the incisors, crowding in the lower arch, and generalized gengival hyperplasia, probably induced by cyclosporine assumption.

Panoramic radiograph (Rx-OPT) showed the absence of external radicular resorption as well as parodontal or bone lesions (Figure 3a). The latero-lateral rx (Figure 3b) and the relative cephalometric analysis according to Giannì (Table 1) revealed the presence of a skeletal Class I tending to Class III (subspinale(A)-nasion(N)-suprmanetlae(B) angle $(\mathrm{ANB})=1)$, skeletal deep-bite, normo-divergence, and normal mandibular growth with horizontal growth pattern.

An interesting finding was constituted by a particular conformation of the hands, presenting short phalanges (Figure 4).

The aims of the treatment were: to correct the skeletal relationship between the upper and lower jaws, to resolve the crowding in the lower arch, to reach a dental Class I, and to reduce the gingival hyperplasia.

After a plurispecialized medical examination and an oral hygiene and prophylaxis program with recurrent medical examination, the patient was subjected to a treatment divided in three steps:

- orthopedic treatment with Delaire Mask for three and a half years;
- orthodontic treatment of the lower arch with Straight Wire technique. In order to decrease the accumulation of dental plaque, we opted for key techniques of orthodontic management, such as: to avoid molar bands and to involve only the crowded teeth bonding from 3.3 to 4.3 (orthodontic archwire sequence: NiTi $.014, .016, .018$ and steel .014 ), to use small-sized brackets, to remove carefully the excessive composite, to plan frequent follow-up, the final upper and lower removable retainers; and

- laser gingivectomy (Figures $2 \mathrm{c}$ and $2 \mathrm{~d}$ ) with laser diodes (super pulsed, 4 Watt, fibre $400 \mu \mathrm{m}$ ).

Final extraoral (Figures 1c and 1d) and intraoral photos (Figure 5a-e) were acquired. Rx-OPT (Figure 3c) and lateral teleradiography (L-L rx) (Figure 3d) were performed.

At the end of orthodontic treatment, esthetic reconstructions of the upper central incisors to close midline diastema using composite resin materials were performed (Figure $5 \mathrm{f}$ ).

\section{3 | RESULTS}

The orthopedic/orthodontic treatment has improved both skeletal and dental relationships (orthodontic camouflage), reaching a good dental arches alignment. The laser surgery solved the gingival hyperplasia. The observance of a proper domestic oral hygiene by the patient contributed to the 
T A B L E 1 Cephalometric analysis according to Jarabak

\begin{tabular}{|llll} 
Cephalometric L-L study & \multicolumn{1}{l}{ Normal value } & $\mathbf{1 1}$ years & $\mathbf{1 7}$ years \\
\hline \multicolumn{2}{|l}{ Sagittal skeletal relationships $\left(^{\circ}\right)$} & & \\
\hline SNA & $82 \pm 2$ & 77 & 79 \\
\hline SNB & $80 \pm 2$ & 76 & 78 \\
ANB & $2 \pm 2$ & 1 & 1
\end{tabular}

Vertical skeletal relationships $\left({ }^{\circ}\right)$

\begin{tabular}{llll} 
Ar-S-N & $122 \pm 5$ & 124 & 130 \\
S-Ar-Go & $143 \pm 6$ & 145 & 137 \\
\hline Ar-Go-Me & $120 \pm 5$ & 124 & 124 \\
Ar-Go-N & $50 \pm 2$ & 53 & 53 \\
N-Go-Me & $70 \pm 3$ & 71 & 71 \\
S+Ar+Go & $396 \pm 2$ & 393 & 394 \\
S-N/Go-Me & $32 \pm 5$ & 32 & 30
\end{tabular}

\section{Vertical skeletal relationships $(\mathbf{m m})$}

$\begin{array}{llll}\text { N-Me } & & 116 & 139 \\ \text { S-Go } & & 65 & 81 \\ \text { \% Jarabak } & 59 \%-63 \% & 55 \% & 58 \%\end{array}$

\section{Sagittal plane (mm)}

$\begin{array}{llll}\text { S-N } & 71 \pm 3 & 70 & 78 \\ \text { Go-Me } & 71 \pm 5 & 60 & 78 \\ \text { Cranial base length }(\mathbf{m m}) & & & \\ \text { S-N } & 71 \pm 3 & 70 & 78 \\ \text { S-Ar } & 32 \pm 2 & 31 & 38\end{array}$

Mandibolar component (mm)

$\begin{array}{llll}\text { Ar-Go } & 44 \pm 5 & 43 & 55 \\ \text { Go-Me } & 71 \pm 5 & 60 & 78\end{array}$

Dentoalveolar component $\left({ }^{\circ}\right)$

\begin{tabular}{llll} 
U1toSN & $102 \pm 2$ & 112 & 116 \\
L1toGoMe & $90 \pm 3$ & 90 & 90 \\
Interincisal angle & $130 \pm 5$ & 138 & 140 \\
\hline
\end{tabular}

ANB: subspinale(A)-nasion(N)-suprmanetlae(B) angle; SNA, sella(S)-nasion(N)subspinale(A) angle; SNB, sella(S)-nasion(N)-supramentale(B) angle.

maintenance of a correct oral health status during the remote medical controls.

\section{4 | DISCUSSION}

$\mathrm{PH}$ and complications resulting from its management can lead to severe impairments of different organs. ${ }^{23}$

The first discussion of the oral manifestation of the PH was performed by Glass in his case report (1973), regarding oral findings in a patient diagnosed with $\mathrm{PH}$ (postmortem). ${ }^{24}$

To date, few papers have described the oral complications of this disease. ${ }^{8,10,25-31}$ Oral manifestations of hyperoxaluria are rare. Among the main complications: hypodontia and microdontia, dental pain, ${ }^{26,30}$ root resorption, ${ }^{31}$ periodontal diseases $^{8,10}$ and bone alterations such as radiolucencies in the

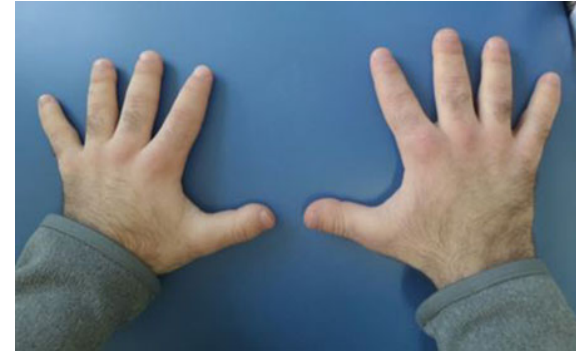

F I G U R E 4 A conformation of the hands-particular

jaws $^{32}$ are described. ${ }^{22}$ These alterations are due to both the primary disease and to secondary parathyroidism due to the chronic renal failure, as well as to the transplantation sequelae and protracted pharmacological treatments. ${ }^{20}$ Bone and tooth resorption may be the result of chronic inflammation and the presence of osteoclastic cells surrounding the oxalate crystal deposits. ${ }^{33}$

The management of these patients requires a multidisciplinary approach and, as early as possible, a dental intervention. Besides the complications mentioned above, in consideration of an orthodontic treatment in such patients, some observations should be made. In particular, an important consideration with orthodontic implication is the altered $\mathrm{Ca} / \mathrm{P}$ metabolism and bone turnover linked to the kidney-liver transplantation and the related immunosuppressive therapy. Moreover, dialyzed and transplanted patients demonstrate a premature loss of the osseous tissue (compact alveolar lamina, alveolar bone), which may lead to gomphosis, and impaired bone trabeculation and demineralization resulting in resorption of the periapical tissue, and even fracture of the maxilla and mandible ${ }^{22}$ as well as in other rare diseases. ${ }^{34}$ Our pediatric patient was under corticosteroid treatment which, in animal studies, has been shown to interfere with orthodontic tooth movement rate and tissue reaction. ${ }^{35}$ Furthermore, it was observed that chronic steroid ingestion leads to an increased biological reaction to mechanical perturbation indicating that the orthodontic force level should be reduced and controlled more frequently in patients on chronic steroid treatment. ${ }^{36}$

For these reasons, frequent and accurate orthodontic examinations were necessary in order to check the dental movements and the hard tissues alterations ${ }^{31}$ as well as for other rare diseases characterized by altered $\mathrm{Ca} / \mathrm{P}$ metabolism. ${ }^{37-39}$ Furthermore, the gingival hyperplasia due to cyclosporine therapy had to be treated, as put at risk the periodontum status.

\section{5 | CONCLUSIONS}

It is clear that this kind of patient requires an accurate anamnesis, a well-timed intervention, a careful dental-periodontal evaluation, good oral health standards, and an appropriate 


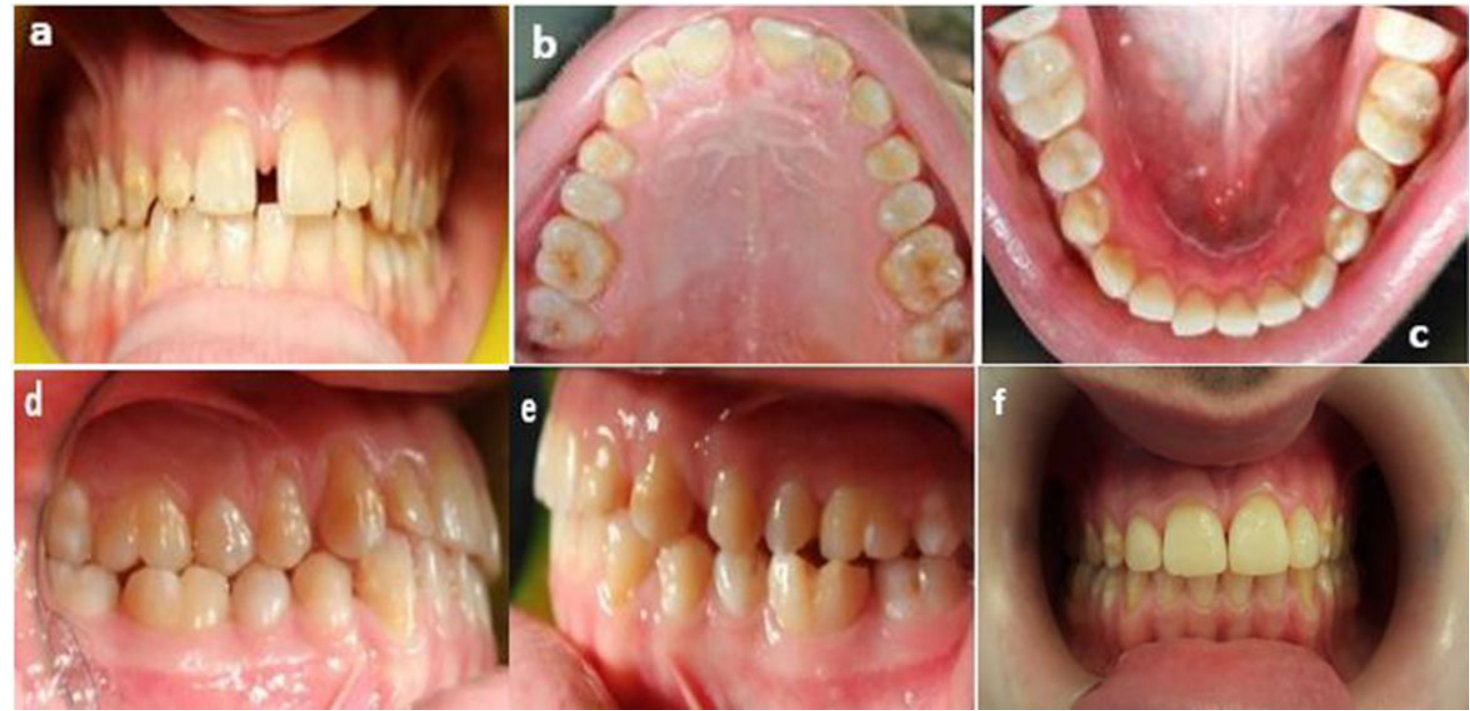

F I G U R E 5 Intraoral photo after treatment: (a) frontal view; (b) occlusal upper view; (c) occlusal lower view; (d) lateral right view; (e) lateral left view; (f) frontal view of the patient's smile after upper incisor reconstructions

management of the orthodontic strengths in order to reach positive and stable in time results.

Early diagnosis and consequent early intervention are very important, especially in patients with rare diseases.

Our multidisciplinary approach allowed us to achieve acceptable results, avoiding the recourse to invasive surgical techniques and increasing at the same time the small patient compliance and his quality of life.

\section{ACKNOWLEDGMENT}

This research did not receive any specific grant from funding agencies in the public, commercial, or not-for-profit sectors.

\section{CONFLICT OF INTEREST}

The authors declare that they have no conflict of interest.

\section{FUNDING}

No kind of funding supports this research.

\section{INFORMED CONSENT}

Informed consent was obtained from all individual participants included in the study.

\section{DECLARATION OF PATIENT CONSENT}

The authors certify that they have obtained all appropriate patient consent forms. In the form the patient(s) has/have given his/her/their consent for his/her/their images and other clinical information to be reported in the journal. The patients understand that their names and initials will not be published and due efforts will be made to conceal their identity, but anonymity cannot be guaranteed.

\section{ORCID}

A. P. Cazzolla DDS, PhD (D)

http://orcid.org/0000-0003-0842-7351

K. Zhurakivska DDS

http://orcid.org/0000-0002-2153-0778

\section{REFERENCES}

1. Harambat J, Fargue S, Bacchetta J, Acquaviva C, Cochat P. Primary hyperoxaluria. Int J Nephrol. 2011;2011:864580.

2. Salido E, Pey AL, Rodriguez R, Lorenzo V. Primary hyperoxalurias: disorders of glyoxylate detoxification. Biochim Biophys Acta. 2012;1822:1453-1464.

3. Cellini B, Oppici E, Paiardini A, Montioli R. Molecular insights into primary hyperoxaluria type 1 pathogenesis. Front Biosci (Landmark Ed). 2012;17:621-634.

4. Johnson SA, Rumsby G, Cregeen D, Hulton SA. Primary hyperoxaluria type 2 in children. Pediatr Nephrol. 2002;17:597-601.

5. Belostotsky R, Seboun E, Idelson GH, et al. Mutations in DHDPSL are responsible for primary hyperoxaluria type III. Am J Hum Genet. 2010;87:392-399.

6. Bhasin B, Urekli HM, Atta MG. Primary and secondary hyperoxaluria: understanding the enigma. World J Nephrol. 2015;4: 235-244.

7. Leumann E, Hoppe B. The primary hyperoxalurias. J Am Soc Nephrol. 2001;12:1986-1993.

8. Hedemark A, Bang G, Gammeltvedt AT, Anda S. Dental and jaw changes in primary hyperoxaluria. J Oral Pathol Med. 1989; 18:586-589.

9. Rahima MM, DiMauro MP. Primary hyperoxaluria in a pediatric dental patient: case report. Pediatr Dent. 1992;14:260-262. 
10. Panis V, Tosios KI, Gagari E, Griffin TJ, Damoulis PD. Severe periodontitis in a patient with hyperoxaluria and oxalosis: a case report and review of the literature. J Periodontol. 2010;81:14971504.

11. Mitsimponas KT, Wehrhan T, Falk S, Wehrhan F, Neukam FW, Schlegel KA. Oral findings associated with primary hyperoxaluria type I. J Craniomaxillofac Surg. 2012;40:e301-e306.

12. American Academy of Pediatric Dentistry. Guideline on dental management of pediatric patients receiving chemotherapy, hematopoietic cell transplantation, and/or radiation therapy. Pediatr Dent. 2016;38(6):334-342.

13. Sheller B, Williams B. Orthodontic management of patients with hematologic malignancies. Am J Orthod Dentofacial Orthop. 1996; 109:575-580.

14. van Woerden CS, Groothoff JW, Wanders RJ, Davin JC, Wijburg FA. Primary hyperoxaluria type 1 in The Netherlands: prevalence and outcome. Nephrol Dial Transplant. 2003;18: 273-279.

15. Cochat P, Koch Nogueira PC, Mahmoud MA, Jamieson NV, Scheinman JI, Rolland MO. Primary hyperoxaluria in infants: medical, ethical, and economic issues. J Pediatr. 1999;135: 746-750.

16. Diallo O, Janssens F, Hall M, Avni EF. Type 1 primary hyperoxaluria in pediatric patients: renal sonographic patterns. AJR Am J Roentgenol. 2004;183:1767-1770.

17. Daudon M, Jungers P. Clinical value of crystalluria and quantitative morphoconstitutional analysis of urinary calculi. Nephron Physiol. 2004;98:p31-p36.

18. Gibbs DA, Watts RW. The variation of urinary oxalate excretion with age. J Lab Clin Med. 1969;73:901-908.

19. Cochat P, Fargue S, Harambat J. Primary hyperoxaluria type 1: strategy for organ transplantation. Curr Opin Organ Transplant. 2010;15:590-593.

20. Olczak-Kowalczyk D, Gozdowski D, Pawlowska J, Grenda R. The status of dental and jaw bones in children and adolescents after kidney and liver transplantation. Ann Transplant. 2012;17:72-81.

21. Wondimu B, Nemeth A, Modeer T. Oral health in liver transplant children administered cyclosporin A or tacrolimus. Int J Paediatr Dent. 2001;11:424-429.

22. Kulak CA, Borba VZ, Kulak Junior J, Custodio MR. Bone disease after transplantation: osteoporosis and fractures risk. Arq Bras Endocrinol Metabol. 2014;58:484-492.

23. Jamieson NV, Study EPT. A 20-year experience of combined liver/kidney transplantation for primary hyperoxaluria (PH1): the European PH1 Transplant Registry experience 1984-2004. Am J Nephrol. 2005;25:282-289.

24. Glass RT. Oral manifestations in primary hyperoxaluria and oxalosis. Report of a case. Oral Surg Oral Med Oral Pathol. 1973;35:502-509.

25. Bunte M, Bitter K, Gross UM, Kraft D, Offermann G. [Dentomaxillary destructions in oxalosis]. Dtsch Zahnarztl Z. 1977;32:617-620.
26. Fantasia JE, Miller AS, Chen SY, Foster WB. Calcium oxalate deposition in the periodontium secondary to chronic renal failure. Oral Surg Oral Med Oral Pathol. 1982;53:273-279.

27. Wysocki GP, Fay WP, Ulrichsen RF, Ulan RA. Oral findings in primary hyperoxaluria and oxalosis. Oral Surg Oral Med Oral Pathol. 1982;53:267-272.

28. Boyce BF, Prime SS, Halls D, et al. Does osteomalacia contribute to development of oral complications of oxalosis. Oral Surg Oral Med Oral Pathol. 1986;61:272-277.

29. Lapointe HJ, Listrom R. Oral manifestations of oxalosis secondary to ileojejunal intestinal bypass. Oral Surg Oral Med Oral Pathol. 1988;65:76-80.

30. Moskow BS. Periodontal manifestations of hyperoxaluria and oxalosis. J Periodontol. 1989;60:271-278.

31. Rinksma AJ, Oosterhuis JW, Wolvius EB, van der Wal KG. Oral manifestations of oxalosis: a case report and review of the literature. J Oral Maxillofac Surg. 2008;66:1953-1956.

32. Benmoussa L, Renoux M, Radoi L. Oral manifestations of chronic renal failure complicating a systemic genetic disease: diagnostic dilemma. case report and literature review. J Oral Maxillofac Surg. 2015;73:2142-2148.

33. Guerra EN, Vianna L, Sobreira MN, de Araujo FN, de Melo NS. Oral manifestations of hyperoxaluria. J Craniofac Surg. 2011;22:2191-2192.

34. Cazzolla AP, Troiano G, Zhurakivska K, et al. Langerhans cell histiocytosis of the maxillae in a child treated only with chemotherapy: a case report. J Med Case Rep. 2017;11:130.

35. Verna C, Hartig LE, Kalia S, Melsen B. Influence of steroid drugs on orthodontically induced root resorption. Orthod Craniofac Res. 2006;9:57-62.

36. Kalia S, Melsen B, Verna C. Tissue reaction to orthodontic tooth movement in acute and chronic corticosteroid treatment. Orthod Craniofac Res. 2004;7:26-34.

37. Favia G, Lacaita MG, Limongelli L, et al. Hyperphosphatemic familial tumoral calcinosis: odontostomatologic management and pathological features. Am J Case Rep. 2014;15:569-575.

38. Lacarbonara M, Cazzolla AP, Lacarbonara VA, Di Venere D, Capogreco M, Marzo G. Prolidase deficiency: dento-facial aspects in a paediatric patient. Eur J Paediatr Dent. 2014;15:224-228.

39. Leopardi M, Parziale V, Ciavarella D, Chimenti C. Maxillary bone lesions in McCune-Albright syndrome: a case report. Prog Orthod. 2011;12:84-89.

How to cite this article: Cazzolla AP, Zhurakivska K, Ciavarella D, et al. Primary hyperoxaluria: Orthodontic management in a pediatric patient: A case report. Spec Care Dentist. 2018;38:259-265. https://doi.org/10.1111/scd.12302 